\title{
Hybrid-Modulation-Based Control Technique for Reduction of Output Voltage Ripples in Frequency-Modulated Switch-Mode Power Converters
}

\author{
Deniss Stepins ${ }^{1}$, Jin Huang ${ }^{2}$, Janis Audze ${ }^{3}$ \\ ${ }^{1,3}$ Institute of Radioelectronics, Riga Technical University, Latvia \\ ${ }^{2}$ School of Electrical and Electronic Engineering, Huazhong University of Science and Technology, China
}

\begin{abstract}
Article Info
Article history:

Received Apr 1, 2018

Revised Apr 24, 2018

Accepted Jul 1, 2018

\section{Keyword:}

Electromagnetic interference Frequency modulation Hybrid modulation Ripples Switching power converters
\end{abstract}

\begin{abstract}
In this paper a novel control technique for switching-frequency-modulated switch-mode power converters (SMPC) operating in discontinuous conduction mode is proposed. The use of the technique leads to significant reduction in peak-to-peak output voltage and peak currents increased due to straightforward application of switching frequency modulation (SFM). The technique is based on hybrid modulation scheme in which both switching frequency and duty ratio are modulated simultaneously by the same modulation signal. Theoretical analysis and experimental verification of the proposed technique are presented in details. Both computer simulations and experiments show that switching-frequency-modulated SMPC with the proposed control technique in comparison to SMPC without SFM has appreciably lower conducted electromagnetic emissions, at the cost of slightly increased peak-to-peak output voltage and peak currents.
\end{abstract}

Copyright $\left(C_{0} 2018\right.$ Institute of Advanced Engineering and Science. All rights reserved.

\section{Corresponding Author:}

Deniss Stepins,

Institute of Radioelectronics,

Riga Technical University, 12 Azenes street, Riga, Latvia.

Email: deniss.stepins@rtu.lv

\section{INTRODUCTION}

With an ever increasing number of electrical and electronic devices (e.g. personal computers, TV sets, vacuum cleaners, etc.), efficient electric power conversion has become a hot topic of research. DC/DC or AC/DC electric power converters which are used for efficient electric power conversion in electronic equipment are dominantly switch-mode ones. Switch-mode power converters (SMPC) have distinct advantages over other types of power converters (e.g. linear power supplies) - mainly higher efficiency, lower size and weight [1], [2]. However owing to rapidly switching semiconductor devices with high voltage and current change rates they are major sources of electromagnetic interference (EMI) both conducted and radiated [3].

Conducted EMI is usually reduced by using passive or active EMI filters, interleaving, softswitching techniques, spread spectrum techniques, etc. [4] - [11]. Since every conducted EMI suppression technique has its own advantages and disadvantages, often they are used in combination with other EMI reduction approaches. For example, it is often not enough to use spread spectrum approach alone to reduce conducted EMI significantly and keep it within allowable limits [10]. Spread spectrum technique is often used in combination with passive EMI filtering. In this case passive EMI filter size and weight can be reduced noticeably [12].

This paper deals with the spread spectrum technique based on periodic switching frequency modulation (SFM) applied to SMPC to reduce conducted EMI. In fact, the technique has gained considerable attention during past two decades because of its easiness of implementation and ability not to increase 
weight, size and cost of SMPC. However the main problem with the use of this technique in conventional DC/DC or AC/DC SMPC is that peak-to-peak output voltage and power stage peak currents (e.g. power inductor or power MOSFET currents) can increase significantly [13] - [16]. Increase in peak-to-peak output voltage of SMPC can be very harmful to electronic equipment powered by the SMPC, but increase in peak currents of power magnetic components can lead to increase in losses and even to saturation of a magnetic core of transformers or inductors.

In [13] - [17] the effect of SFM on peak-to-peak output voltage and power stage peak currents of DC/DC SMPC operating in continuous conduction mode (CCM) and discontinuous conduction mode (DCM) was studied in details and some recommendations for proper design of DC/DC SMPC were proposed. However, the recommendations are not sufficiently useful to get low peak-to-peak output voltage and power stage peak currents, especially for switching-frequency-modulated SMPC operating in DCM. This is why in this paper a novel control technique for significant reduction of peak-to-peak output voltage and power stage peak currents in switching-frequency-modulated SMPC is proposed. The control technique is based on hybrid modulation scheme in which both switching frequency and duty cycle are modulated by the same modulation signal. Along with appreciable conducted EMI reduction, the technique also decreases significantly peak-to-peak output voltage and power stage peak currents increased due to the use of SFM. In order to show usefulness of the proposed technique a simple analog circuit based on analog multiplier will also be proposed and analyzed.

The proposed control technique can be applied to both classical single-switch non-isolated (e.g. buck, boost, buck-boost) and isolated (e.g. flyback, forward) SMPC topologies operating in DCM. The proposed method is not suitable for SMPC operating in CCM, because in this case variations of duty ratio can lead to large low-frequency ripples in SMPC output voltage.

The paper is organized as follows. In section 2 the effect of the proposed hybrid modulation scheme on DCM boost DC/DC SMPC peak-to-peak output voltage and power stage peak currents will be studied analytically and by computer simulations. In section 3 thorough experimental verification of the proposed technique will be performed. Finally, conclusions are given in Section 4.

\section{THEORETICAL ANALYSIS OF THE PROPOSED CONTROL TECHNIQUE}

Based on the analysis presented in our papers [15] - [17] and after analyzing expressions of output ripple voltage for traditional switching-frequency-modulated single-switch SMPC (e.g. buck, boost, buckboost, forward and flyback) operating in DCM it can be shown that general expression of peak-to-peak output voltage when SFM is enabled is as follows:

$$
V_{F M p p}=\max \left\{v_{L F}(t)+v_{\text {envHF }}(t)\right\}-\min \left\{v_{L F}(t)-v_{\text {envHF }}(t)\right\}
$$

where $v_{L F}(t)$ is low-frequency (LF) ripple of output voltage caused by SFM; $v_{e n v H F}(t)$ is high-frequency (HF) ripple envelope. The LF ripples in DCM are due to the fact that averaged inductor, diode and transistor switch currents are switching-frequency-dependant [17]. The envelope of HF ripple in unmodulated SMPC is constant, but in switching-frequency-modulated SMPC it is variable (because switching frequency changes in time). Both $v_{L F}(t)$ and $v_{e n v H F}(t)$ are functions of instantaneous switching frequency $f_{s w}(t)$ and instantaneous duty ratio $d(t)$ :

$$
\begin{aligned}
& v_{-} L F(\mathrm{t})=\psi_{-} 1\left[\mathrm{~d}(\mathrm{t}), \mathrm{f} \_\mathrm{sw}(\mathrm{t})\right] \\
& v_{\text {envHF }}(t)=\psi_{2}\left[d(t), f_{s w}(t)\right],
\end{aligned}
$$

Where

$$
\begin{aligned}
& d(t)=D+\tilde{d}(t), \\
& f_{s w}(t)=f_{s w 0}+\Delta f_{s w} m(t),
\end{aligned}
$$

where $D$ is average duty ratio; $\tilde{d}(t)$ is variable component of duty ratio; $\Delta f_{s w}$ is switching frequency deviation; $m(t)$ is modulation waveform with unitary amplitude; $f_{s w 0}$ is central switching frequency. Note further in the analysis it will be assumed that $m(t)$ is periodic and $f_{m}$ is modulation frequency.

For frequencies $f_{m}$ lower than open loop gain crossover frequency $\left(f_{\text {cross }}\right)$ feedback loop changes duty ratio with the purpose to reduce the output voltage LF ripple. In order to simplify our analysis let's assume that $f_{m}>f_{\text {cross }}$. In this case $d(t)$ is almost constant and equals $D$ approximately. 
For quite large $\Delta f_{S W}, V_{F M p p}$ and magnetic components peak currents can increase significantly in DCM in comparison to unmodulated case [16], [17]. Therefore it is important to propose a control technique to reduce peak-to-peak output voltage and peak currents increased due to straightforward application of SFM.

Now we are going to show some theoretical analysis in order for a reader to better understand the idea. Assuming that $f_{m}>f_{\text {cross }},(2)$ and (3) can be overwritten as follows:

$$
\begin{aligned}
& v_{L F}(t)=\psi_{1}\left[D+\delta(t), f_{s w}(t)\right] \\
& v_{e n v H F}(t)=\psi_{2}\left[D+\delta(t), f_{s w}(t)\right]
\end{aligned}
$$

where $\delta(t)$ is time-dependant component of the duty ratio which should be generated and introduced into a non-inverting input of the control block comparator so that

$$
\text { V_FMpp }=\text { V_pp }
$$

where $V_{p p}$ is peak-to-peak output ripple voltage of unmodulated (without SFM) SMPC. In order to derive $\delta(t)$, expressions for $v_{L F}(t)$ and $v_{e n v H F}(t)$ should be known and equation (8) with respect to $\delta(t)$ then should be solved.

For switching frequencies up to several hundreds of $\mathrm{kHz}$ electrolytic capacitors are often used at outputs of SMPC. Since for electrolytic capacitors at frequencies $>50 \mathrm{kHz}$ usually equivalent series resistance (ESR) is much higher than capacitive reactance, then in order to simplify our analysis it will be assumed that HF ripples are due to the ESR only.

It can be proved that for single-switch SMPC (e.g. buck, boost, buck-boost, forward and flyback) with typical output electrolytic capacitor general expression for HF ripple is as follows:

$$
v_{e n v H F}(t)=K \frac{d(t)}{2 f_{s w}(t)}
$$

where $K$ is SMPC-topology-dependant coefficient, which e.g. for boost SMPC is as follows [17]:

$$
K=\frac{r_{c} V_{i n}}{L}
$$

where $V_{\text {in }}$ is input DC voltage; $L$ is the power inductor's inductance; $r_{c}$ is ESR of the output capacitor.

General expression for the LF ripple $v_{L F}(t)$ can be found after deriving expressions for AC component of averaged current $\left(\left\langle i_{e}\right\rangle\right)$ before the output capacitor, applying the Laplace transform and deriving expression for the LF ripple in s-domain [17] as follows:

$$
v_{L F}(s)=\tilde{i_{e}}(s) \frac{H_{o u t}(s)}{1+T(s)}
$$

where $H_{\text {out }}(s)$ is output voltage to $i_{e}$ transfer ratio (in case of boost SMPC, it is output voltage to diode current transfer ratio); $T(s)$ is open loop gain; $\widetilde{i_{e}}(s)$ is AC component of $\left\langle i_{e}\right\rangle$ in s-domain. In general case:

$$
<i_{e}>=F \frac{(d(t))^{2}}{f_{s w}(t)}
$$

where $F$ for e.g. boost SMPC [15], [17] is as follows:

$$
F=\frac{V_{\text {in }}^{2}}{2 L\left(V_{\text {out }}-V_{\text {in }}\right)}
$$

In time domain the LF ripple can be obtained by applying inverse Laplace transform of (11).

Despite the fact that optimum $\delta(t)$ for which $V_{F M p p}$ is minimum can be found by solving equation (8) and using (1), (9) and (11), this is, firstly, very complicated task, and secondly, it would be very difficult to generate such a complex $\delta(t)$ in practice. This is why we are to derive simple approximate expression for 
$\delta(t)$, which would give quite high reduction of $V_{F M p p}$ increased due to the use of SFM. We can find the approximate expression by solving two equations separately: one for the variable duty ratio component $\delta_{1}(t)$ to get minimum peak-to-peak HF ripple voltage and another for the variable duty ratio component $\delta_{2}(t)$ to get zero peak-to-peak LF ripple voltage. To get minimum peak-to-peak HF ripple voltage the following equation should be solved:

$$
K \frac{D+\delta_{1}(t)}{2\left(f_{s w 0}+\Delta f_{s w} m(t)\right)}=v_{e n v}(t)
$$

where $v_{e n v}(t)$ is envelope of output voltage ripple for unmodulated SMPC:

$$
v_{e n v}(t)=K \frac{D}{2 f_{s w 0}}
$$

After solving (14), $\delta_{1}(t)$ can be found:

$$
\delta_{1}(t)=A_{1} \operatorname{Dm}(t),
$$

where $A_{1}=\Delta f_{s w} / f_{\text {swo }}$.

In order to find $\delta_{2}(t)$ to get zero LF ripples, $\left\langle i_{e}>\right.$ of switching-frequency-modulated SMPC should be constant and equal to $\left\langle i_{e}>\right.$ for SMPC without SFM as follows:

$$
F \frac{\left(D+\delta_{2}(t)\right)^{2}}{f_{s w 0}+\Delta f_{s w} m(t)}=F \frac{D^{2}}{f_{s w 0}}
$$

From this follows that in order to get zero LF ripple, $\delta_{2}(t)$ should be equal to $A_{2} D m(t)$, where $A_{2}=$ $\Delta f_{s w} /\left(2 f_{s w 0}\right)$.

It can be proved also that minimum peak current of magnetic components of switching-frequencymodulated SMPC can be achieved if $\delta(t)$ equals $A_{1} D m(t)$, because the peak current for unmodulated SMPC is equal to $E D / f_{s w 0}$ (where $E=V_{i n} / L$ for boost SMPC).

Based on the theoretical analysis shown above some conclusions can be drawn. Peak-to-peak output voltage and peak currents of power magnetic and semiconductor components increased due to the use of SFM can be reduced significantly using the hybrid modulation when switching frequency and duty ratio are modulated simultaneously by the same periodic modulation signal $m(t)$, because approximate $\delta(t)$ equals $A D m(t)$. Optimum value of the parameter $A$ is somewhere between $A_{1}$ and $A_{2}$. This value can be calculated by finding minimum of (1) analytically, numerically or using computer-simulation-based approach. If the latter is used then it is necessary to make many simulations for different values of $A$ in range between $A_{2}$ and $A_{I}$ to find optimum $A$. If the LF ripples are much lower than the HF ripples, optimum $A$ is equal to $\Delta f_{S w} /$ $f_{s w 0}$. If the LF ripples are much higher than the HF ripples, optimum $A$ is equal to $\Delta f_{s w} /\left(2 f_{s w 0}\right)$. Note that the conclusions are valid only when $f_{m}>f_{\text {cross }}$.

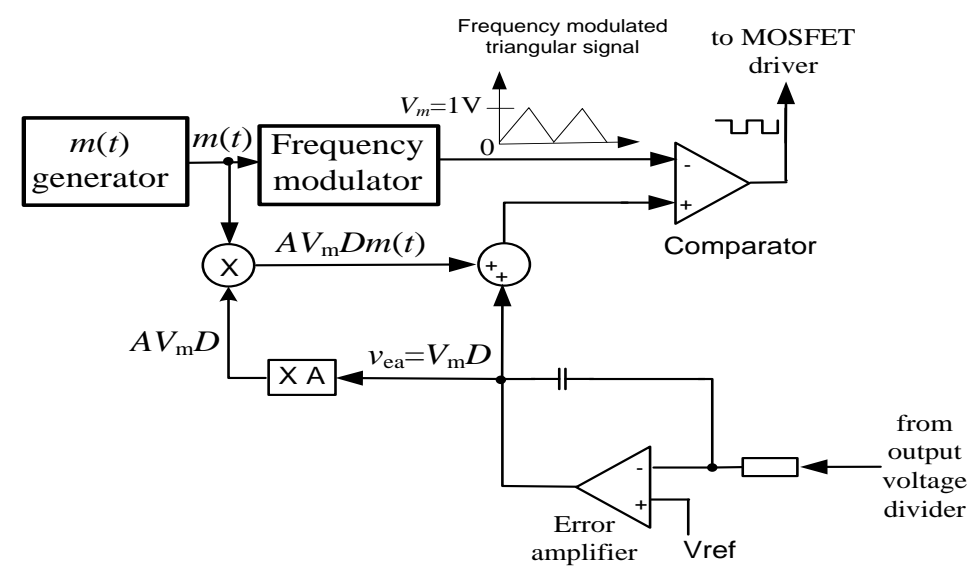


Figure 1. Switching-frequency-modulated SMPC control block with the proposed hybrid modulation

Block diagram of a switching-frequency-modulated SMPC control block with the proposed control technique based on the hybrid modulation is shown in Figure 1. Amplitude of switching frequency variations is equal to $\Delta f_{s w}$, but amplitude of duty ratio variations should be equal to $A$.

In order to show usefulness of the proposed control technique based on the hybrid modulation, a switching-frequency-modulated SMPC simulation model was created in PSIM software as shown in Figure 2. The model was initially simulated without SFM (when $f_{\text {swo }}=100 \mathrm{kHz} ; V_{\text {in }}=12 \mathrm{~V} ; R_{\text {load }}=100 \Omega ; V_{\text {out }}=20 \mathrm{~V}$ ). Output voltage waveform, input current waveform and input current spectrum of unmodulated boost SMPC operating in DCM are depicted in Figure 3 a, Figure 4 a and Figure 5 a. Then the model was simulated with SFM enabled $\left(f_{m}=10 \mathrm{kHz}, \Delta f_{s w}=30 \mathrm{kHz} ; m(t)\right.$ is sine). The results of the simulations are shown in Figure $3 \mathrm{~b}$, Figure $4 \mathrm{~b}$ and Figure $5 \mathrm{~b}$. As it can be seen SFM along with noticeable reduction of input current harmonic amplitudes leads to significant increase in peak-to-peak output ripple voltage and peak inductor current. As shown in Table 1 SFM leads to percentage increase in peak-to-peak output voltage as high as $42.4 \%$ and percentage increase in peak inductor current as high as $41 \%$. However after applying the proposed control method based on hybrid modulation (with $A=0.3$ ), peak-to-peak output voltage and peak inductor current decreased significantly as shown in Figure $3 \mathrm{c}$ and Figure $4 \mathrm{c}$. Along with high reduction of peak-to-peak output voltage and peak inductor current, reduction of input current harmonics amplitudes is almost the same as in case when conventional control scheme (in which switching frequency is modulated only) is used (see Figure $5 \mathrm{c}$ ). It should be noted that the technique proposed is less effective to reduce peak-to-peak output voltage when output capacitor (e.g. ceramic cap.) with capacitive reactance much higher than ESR is used.

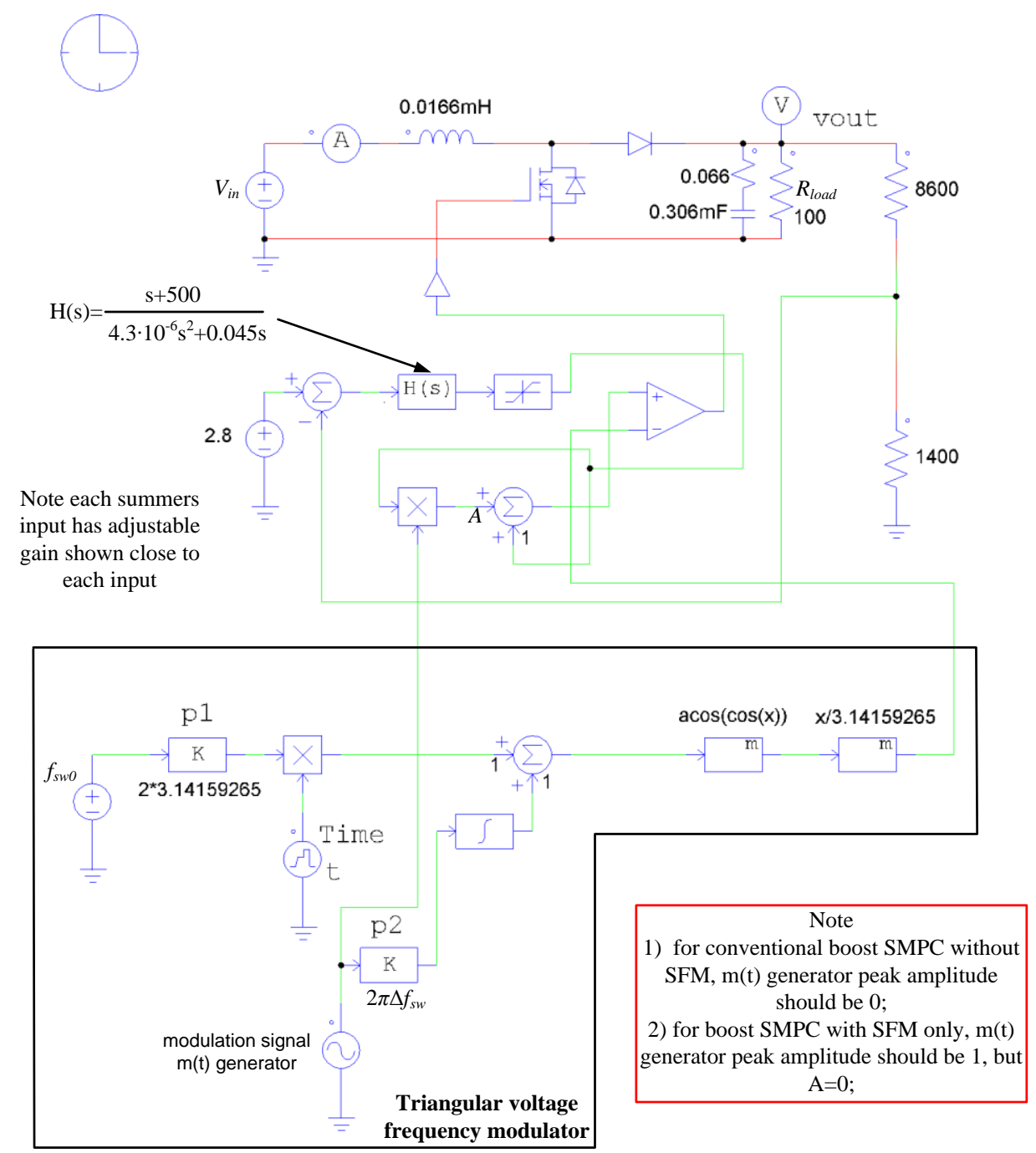

Int J Pow Elec \& Dri Syst, Vol. 9, No. 3, September 2018 : 1272 - 1284 
Figure 2. Boost SMPC simulation model created in PSIM. Note: the model can be used to simulate the boost SMPC without SFM, with SFM alone and with the proposed control technique based on hybrid modulation

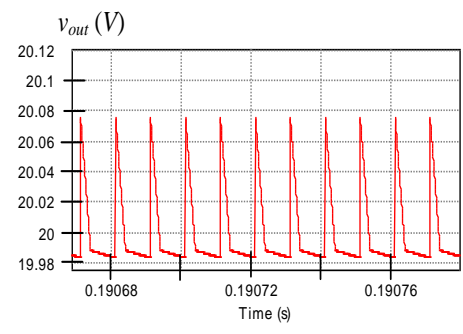

(a)

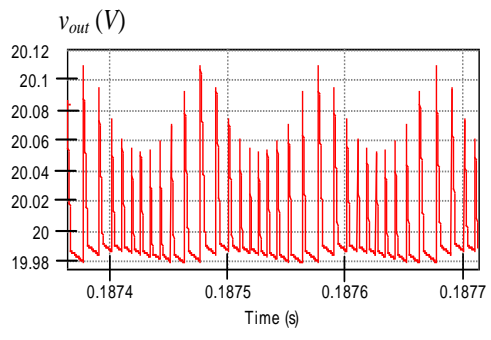

(b)

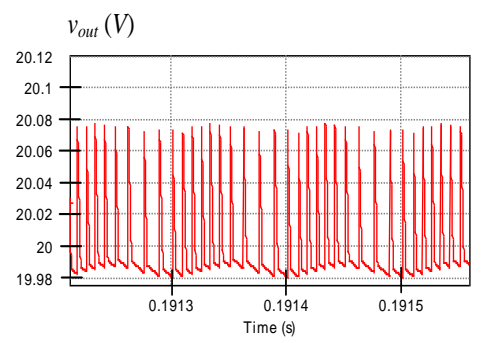

(c)

Figure 3. Simulated output voltage waveforms of boost SMPC in DCM: (a) for boost SMPC without SFM; (b) for boost SMPC with SFM only; (c) for boost SMPC with the hybrid modulation

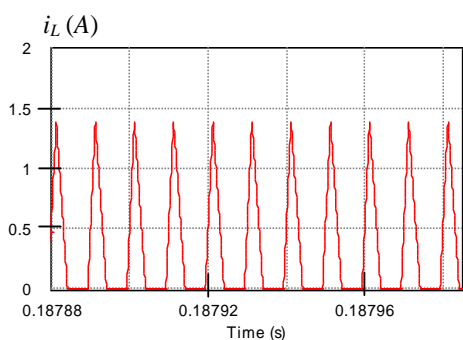

(a)

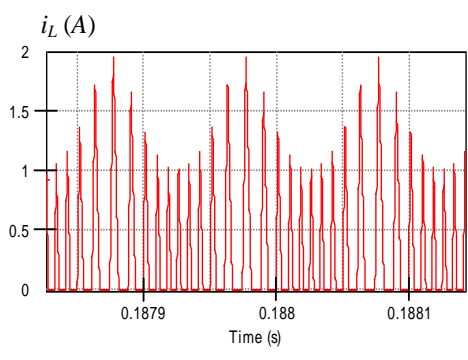

(b)

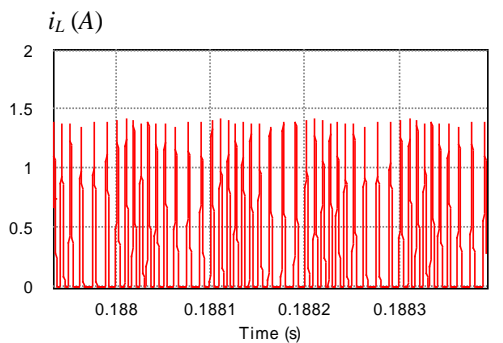

(c)

Figure 4. Simulated inductor current waveforms of boost SMPC in DCM: (a) for boost SMPC without SFM; (b) for boost SMPC with SFM only; (c) for boost SMPC with the hybrid modulation

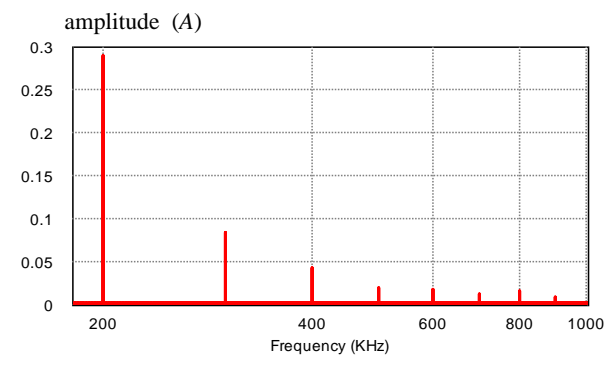

(a)

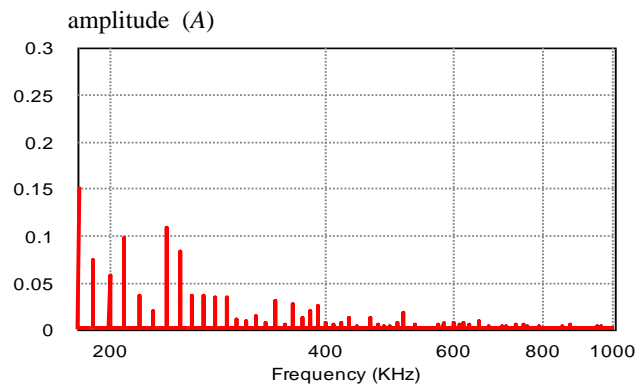

(b)

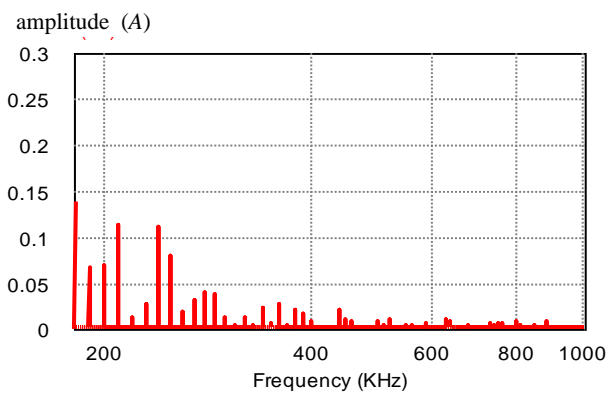

(c)

Figure 5. Simulated input current spectra of boost SMPC in DCM: (a) for boost SMPC without SFM; (b) for boost SMPC with SFM only; (c) for boost SMPC with the proposed control technique based on the hybrid 
modulation

Table 1. Comparison of the simulation results $\left(f_{m}=10 \mathrm{kHz}, f_{s w 0}=100 \mathrm{kHz}, \Delta f_{s w}=30 \mathrm{kHz} ; m(t)\right.$ is sine; $\left.V_{i n}=12 \mathrm{~V}\right)$

\begin{tabular}{cccc}
\hline & boost SMPC without SFM & boost SMPC with SFM & $\begin{array}{c}\text { boost SMPC with the proposed } \\
\text { control technique based on } \\
\text { hybrid modulation }\end{array}$ \\
\hline $\begin{array}{c}\text { peak-to-peak output voltage, } \\
\text { mV }\end{array}$ & 91.3 & 130 & 97 \\
$\begin{array}{c}\text { percentage increase in peak-to- } \\
\text { peak output voltage (in } \\
\text { comparison to SMPC without }\end{array}$ & --- & $42.4 \%$ & $6.2 \%$ \\
$\begin{array}{c}\text { SFM) } \\
\text { peak inductor current, A } \\
\text { percentage increase in peak } \\
\text { inductor current (in comparison } \\
\text { to SMPC without SFM) }\end{array}$ & 1.39 & 1.96 & 1.42 \\
\hline
\end{tabular}

\section{EXPERIMENTAL VALIDATION OF THE PROPOSED CONTROL TECHNIQUE}

\subsection{Experimental setup}

Detailed schematic diagram of an experimental prototype used to verify the usefulness of the proposed control technique is shown in Figure 6. The experimental boost SMPC can be tested without SFM, with conventional SFM and with hybrid modulation. Specifications of the experimental boost SMPC are shown in Table 2.

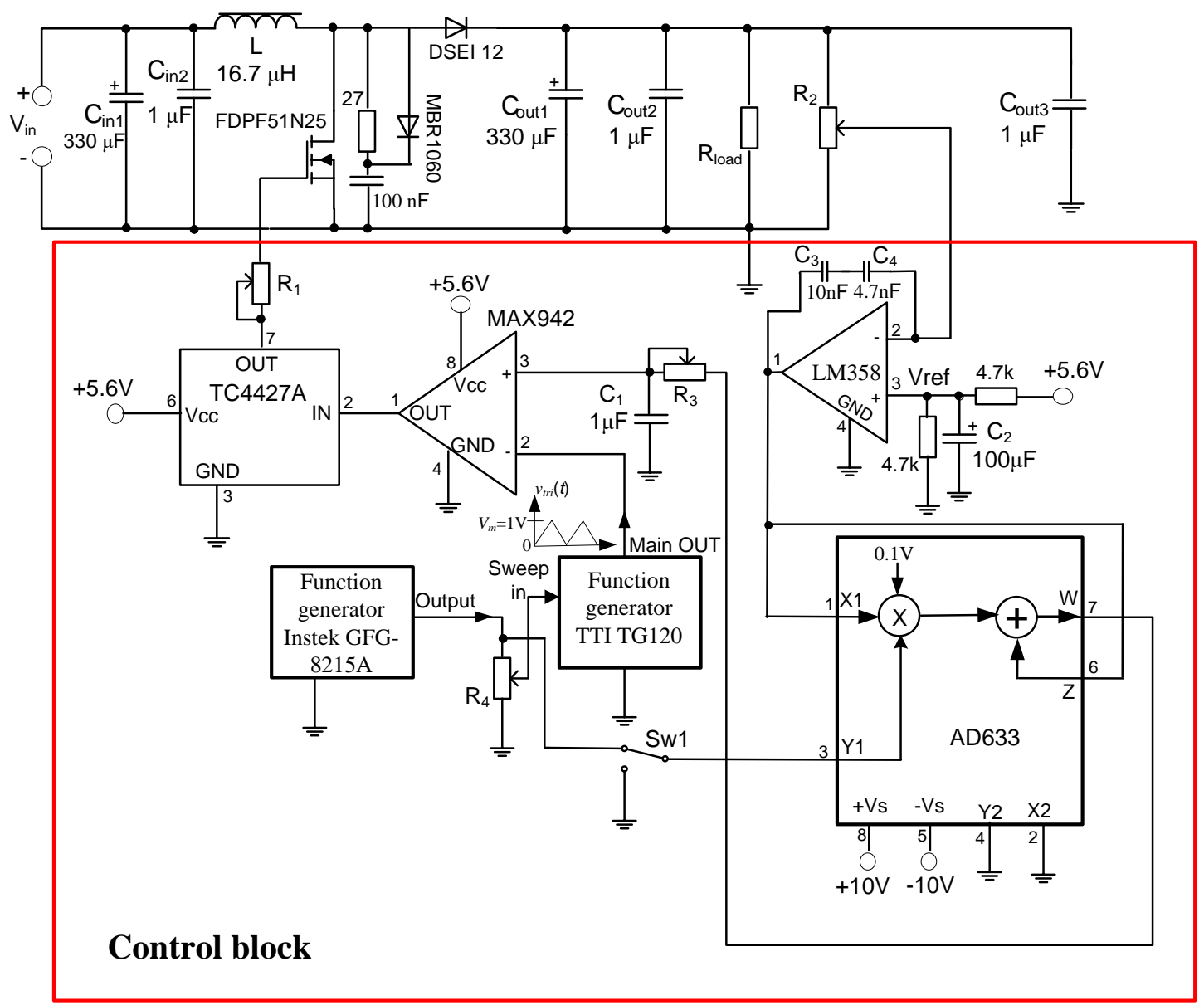

Figure 6. Detailed schematic diagram of the experimental boost SMPC 
Table 2. Experimental prototype specifications

\begin{tabular}{cc}
\hline Input DC voltage & $8 \mathrm{Vdc}-14 \mathrm{Vdc}$ \\
\hline $\begin{array}{c}\text { Output DC voltage } \\
\text { Nominal switching frequency, } f_{\text {sw } 0} \\
\text { Type of control }\end{array}$ & $\begin{array}{c}100 \mathrm{Vdc} \\
\text { Output capacitors } \\
\text { Inductor }\end{array}$ \\
$\begin{array}{c}\text { Analog, voltage mode control } \\
\text { (nominal capacitance of each capacitor is of } 1 \mu \mathrm{F} \text { ); } \\
\text { electrolytic capacitor (nominal capacitance } 330 \mu \mathrm{F} ; \mathrm{ESR} \approx 66 \mathrm{~m} \Omega \text { ) }\end{array}$ \\
\hline
\end{tabular}

Four integrated circuits (ICs) and two function generators are used in the control block. The function generator Instek GFG-8215A is used as modulation signal generator. The function generator TTI TG120 is used as triangular voltage generator. The generator also has voltage controlled oscillator input ("sweep in") for SFM. TC4427A is power MOSFET driver. Potentiometer $\mathrm{R}_{1}$ is used to slow down the power MOSFET switching for the purpose to reduce the power MOSFET and output voltage spikes. Potentiometer $\mathrm{R}_{2}$ is used to adjust desirable DC output voltage. Error amplifier is composed of IC LM358 and simple (Type 1) compensation network $\mathrm{R}_{2} \mathrm{C}_{3} \mathrm{C}_{4}$. Low-pass filter $\mathrm{R}_{3} \mathrm{C}_{1}$ is used to reduce parasitic $\mathrm{HF}$ components in the comparator (IC MAX942) non-inverting pin input voltage. $\mathrm{R}_{3}$ in our experiments was equal to $8.6 \mathrm{k} \Omega$. $\mathrm{C}_{2}$ is used to limit duty ratio at start. Resistor $\mathrm{R}_{4}$ is used to regulate $\Delta f_{s w}$. IC AD633 is analog signal multiplier and summer which is used to implement the hybrid modulation. Voltage Vref is a reference voltage. To disable SFM, the generator Instek should be turned off. If single pole double throw switch (Sw1) is in "up" position, then hybrid modulation is enabled, otherwise it is disabled (if Sw1 is in "down" position only switching frequency is modulated). It should be noted that the proposed control technique can also be implemented digitally using e.g. a microcontroller with suitable program code. This implementation is recommended.

\subsection{Experimental results and discussion}

Initially the boost SMPC was examined when SFM was disabled. Output voltage waveform, input current waveform and conducted EMI levels of unmodulated boost SMPC (with $V_{i n}=12 \mathrm{~V}$ ) operating in DCM are depicted in Figure 7 a, Figure 8 a and Figure 9 a. Then the experimental boost SMPC with SFM enabled was tested. The results (when $f_{m}=9.5 \mathrm{kHz}, f_{\text {sw } 0}=100 \mathrm{kHz}, \Delta f_{\text {sw }}=30 \mathrm{kHz}, m(t)$ is sine, $V_{\text {in }}=12 \mathrm{~V}, R_{\text {load }}=100 \Omega$, $f_{\text {cross }}$ is of several kHz) of the measurements are shown in Figure $7 \mathrm{~b}$, Figure $8 \mathrm{~b}$ and Figure 9 a. As it can be seen SFM along with noticeable reduction of conducted EMI levels leads to significant increase in peak-topeak output ripple voltage and peak inductor current. As shown in Table 3 SFM leads to percentage increase in peak-to-peak output voltage as high as $70.1 \%$ and percentage increase in peak inductor current as high as $42.1 \%$. However after applying the proposed control method based on hybrid modulation (with $A \approx 0.3$ ), peak-to-peak output voltage and peak inductor current decreased significantly as shown in Figure $7 \mathrm{c}$ and Figure $8 \mathrm{c}$ respectively. Along with high reduction of peak-to-peak output voltage and peak inductor current, reduction of the most dominant harmonic in conducted EMI spectrum is almost the same as in case when conventional control scheme (in which switching frequency is modulated only) is used (see Figure $9 \mathrm{~b}$ ).

Table 3. Comparison of the experimental results $\left(f_{m}=9.5 \mathrm{kHz}, f_{s w 0}=100 \mathrm{kHz}, \Delta f_{s w}=30 \mathrm{kHz} ; m(t)\right.$ is sine;

\begin{tabular}{|c|c|c|c|}
\hline & $\begin{array}{c}\text { boost SMPC without } \\
\text { SFM }\end{array}$ & boost SMPC with SFM & $\begin{array}{l}\text { boost SMPC with the } \\
\text { proposed control technique } \\
\text { based on hybrid modulation }\end{array}$ \\
\hline $\begin{array}{l}\text { peak-to-peak output } \\
\text { voltage, } \mathrm{mV}\end{array}$ & 87 & 148 & 95 \\
\hline $\begin{array}{l}\text { percentage increase in } \\
\text { peak-to-peak output } \\
\text { voltage (in comparison to } \\
\text { SMPC without SFM) }\end{array}$ & --- & $70.1 \%$ & $9.2 \%$ \\
\hline peak inductor current, A & 1.78 & 2.53 & 1.86 \\
\hline $\begin{array}{l}\text { percentage increase in } \\
\text { peak inductor current (in } \\
\text { comparison to SMPC } \\
\text { without SFM) }\end{array}$ & --- & $42.1 \%$ & $4.5 \%$ \\
\hline
\end{tabular}




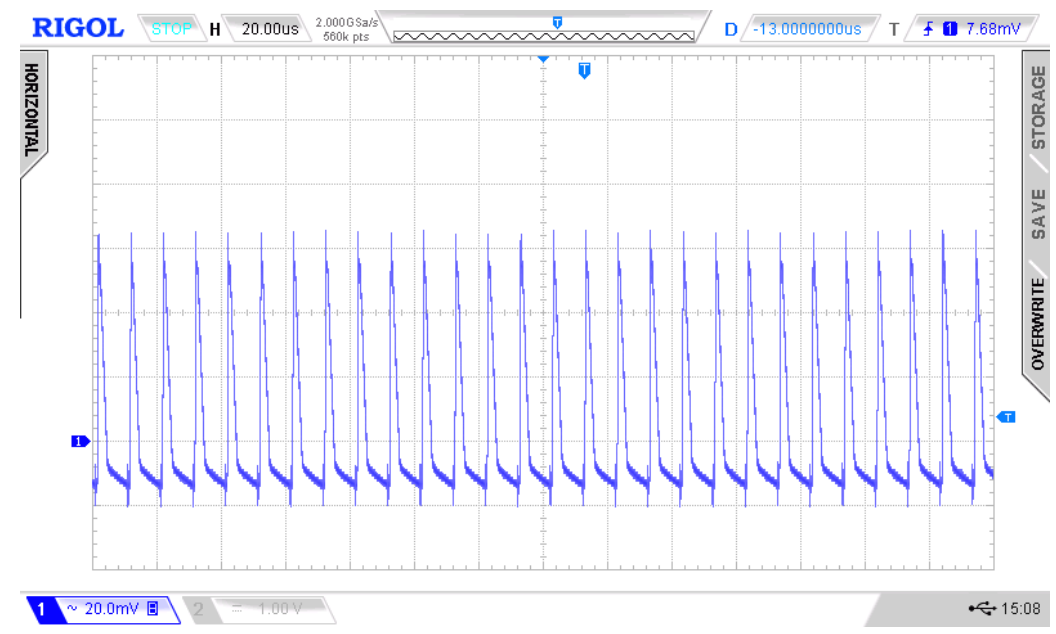

(a)

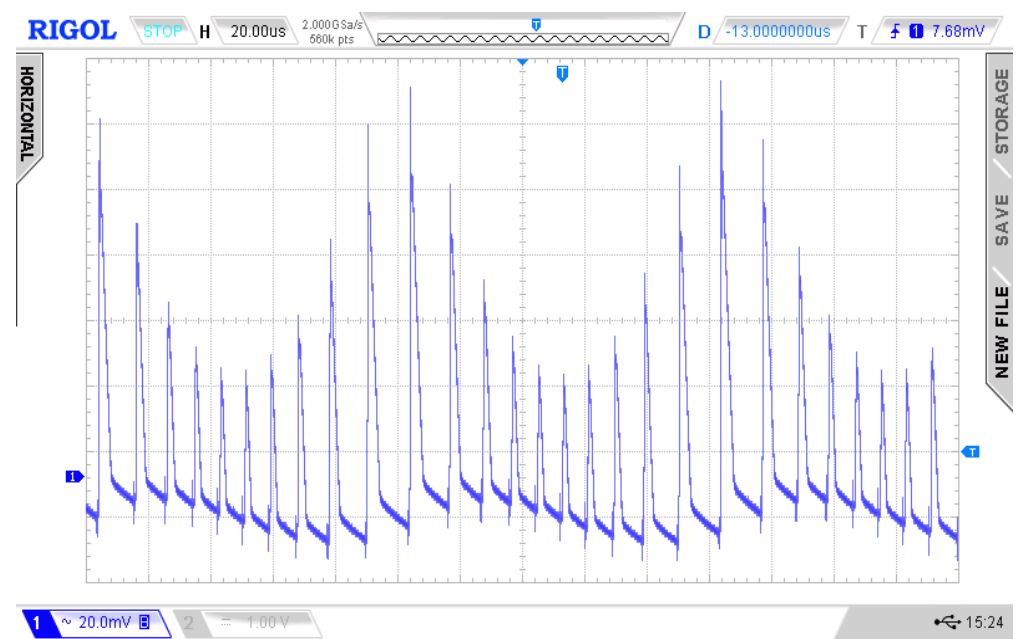

(b)

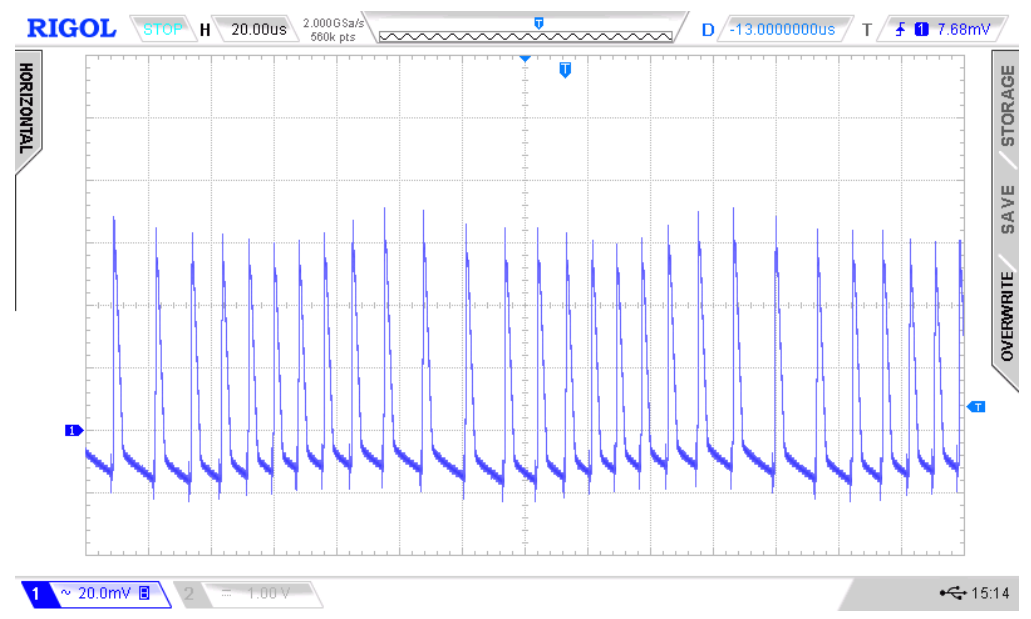

(c)

Figure 7. Experimental output voltage waveforms of boost SMPC in DCM: (a) for boost SMPC without SFM; (b) for boost SMPC with SFM only; (c) for boost SMPC with the hybrid-modulation-based technique. (Scale: $20 \mathrm{mV} / \mathrm{div} ; 20 \mu \mathrm{s} / \mathrm{div}$ ) 


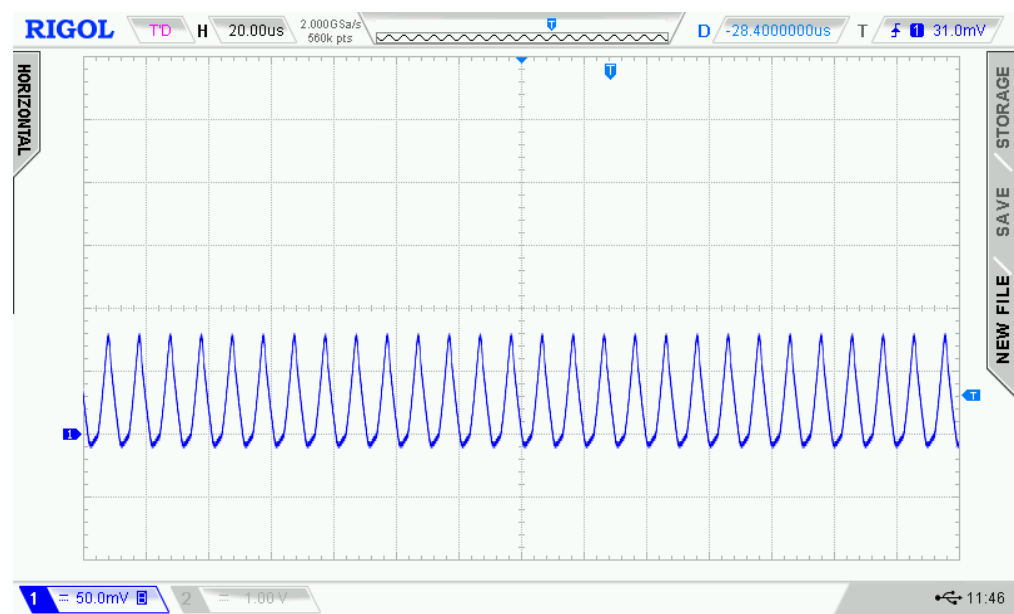

(a)

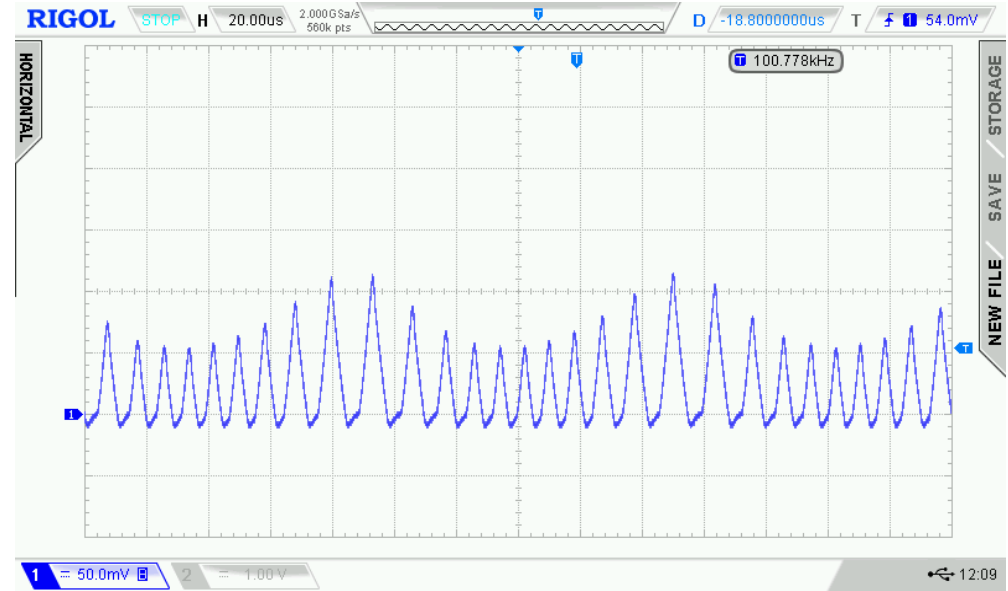

(b)

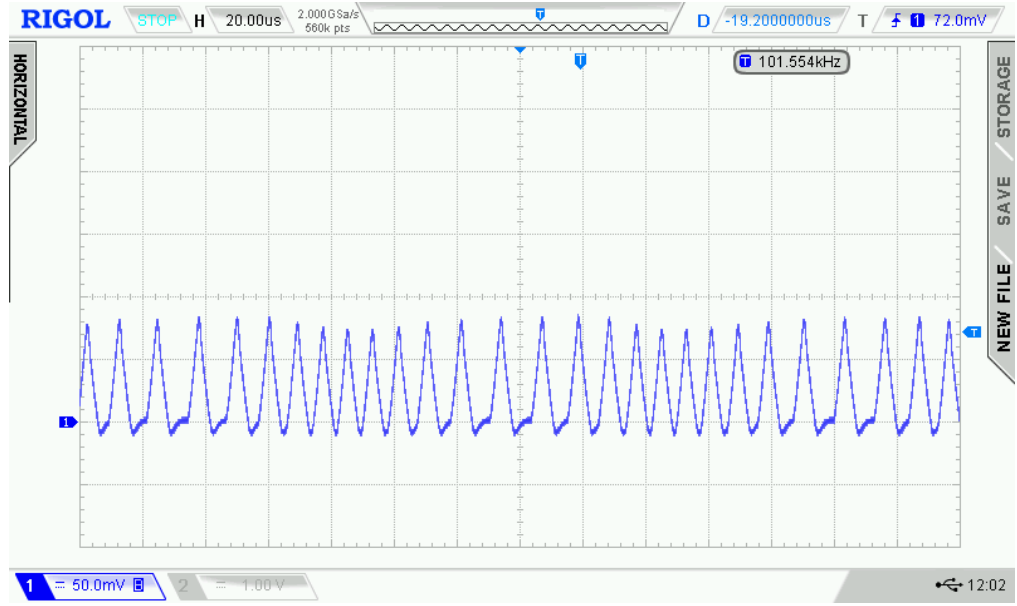

(c)

Figure 8. Experimental inductor current waveforms of boost SMPC in DCM: (a) for boost SMPC without SFM; (b) for boost SMPC with SFM only; (c) for boost SMPC with the hybrid-modulation-based technique. (Scale: $1.11 \mathrm{~A} / \mathrm{div} ; 20 \mu \mathrm{s} / \mathrm{div}$ ) 


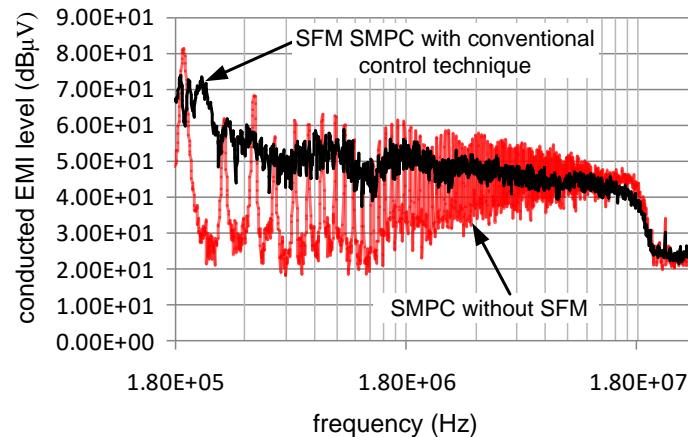

(a)

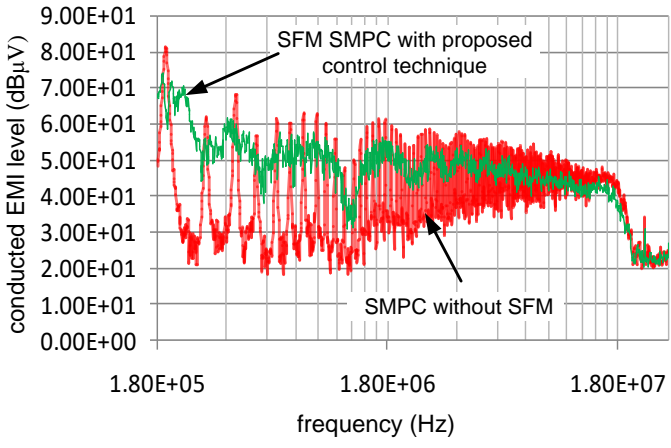

(b)

Figure 9. Experimental conducted EMI spectra of boost SMPC in DCM. Parameters: $f_{m}=9.5 \mathrm{kHz}, f_{s w 0}=100 \mathrm{kHz}$, $\Delta f_{s w}=30 \mathrm{kHz} ; m(t)$ is sine; $V_{i n}=12 \mathrm{~V}$. Note that the spectra were measured using a spectrum analyzer Agilent E4402B with $\mathrm{RBW}=9 \mathrm{kHz}$ and self-made line impedance stabilization network (see Figure 10) in frequency range $180 \mathrm{kHz}-30 \mathrm{MHz}$

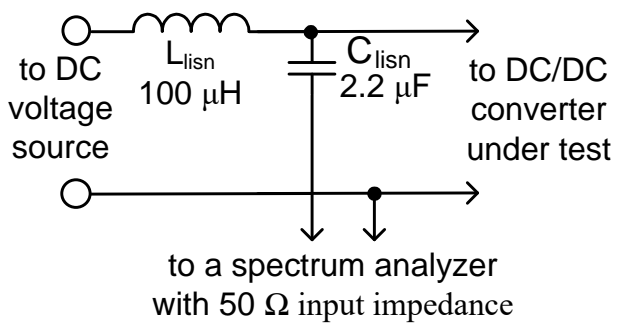

Figure 10. Self-made line impedance stabilization network (LISN) schematic diagram used in the experiments. Note: 1) the self-made LISN is not standard specific device; 2) the spectrum analyzer used in the measurements was connected to the LISN via coaxial cable with length of $9.5 \mathrm{~cm}$ and parasitic capacitance of $10.8 \mathrm{pF}$

Measurements of peak-to-peak output voltage, peak inductor current and conducted emissions levels for other values of $\Delta f_{s w}$, input voltages $(8 \mathrm{~V}-14 \mathrm{~V})$ and output loads showed that the proposed control technique based on the hybrid modulation is very effective too. Measurements of efficiency of the boost SMPC showed that there is no any noticeable deteriorations of the efficiency when the proposed control technique is used. A comparison of the performance characteristics of SMPC with different control techniques is shown in Table 4.

Table 4. Comparison of the performance characteristics of SMPC with different control techniques

\begin{tabular}{|c|c|c|c|}
\hline & $\begin{array}{c}\text { Conventional SMPC } \\
\text { without SFM }\end{array}$ & SMPC with SFM & $\begin{array}{c}\text { SMPC with the proposed } \\
\text { control technique based on } \\
\text { hybrid modulation }\end{array}$ \\
\hline Peak-to-peak output voltage & $\begin{array}{c}+ \\
\text { (the smallest) }\end{array}$ & $\begin{array}{c}- \\
\text { (the highest) }\end{array}$ & $\begin{array}{c}+ \\
\text { (slightly higher than for } \\
\text { conventional SMPC without SFM) }\end{array}$ \\
\hline Conducted emissions levels & (the highest) & $\begin{array}{c}+ \\
\text { (appreciably lower than for } \\
\text { conventional SMPC without } \\
\text { SFM) }\end{array}$ & $\begin{array}{c}+ \\
\text { (appreciably lower than for } \\
\text { conventional SMPC without SFM) }\end{array}$ \\
\hline $\begin{array}{c}\text { Peak power components } \\
\text { currents }\end{array}$ & $\begin{array}{c}+ \\
\text { (the smallest) }\end{array}$ & (the highest) & $\begin{array}{c}+ \\
\text { (slightly higher than for } \\
\text { conventional SMPC without SFM) }\end{array}$ \\
\hline
\end{tabular}




\section{CONCLUSION}

The proposed control technique based on hybrid modulation scheme in which both switching frequency and duty ratio are simultaneously modulated by the same modulation signal is effective technique which can be applied to single-switch switch-mode power converters with classical topologies to reduce peak-to-peak output voltage and peak currents increased due to the use of conventional control scheme in which only switching frequency is modulated. Both computer simulations and experiments show that switching-frequency-modulated switch-mode power converter with the proposed control technique in comparison to that without switching frequency modulation has appreciably lower conducted electromagnetic interference levels, at the cost of slightly increased peak-to-peak output voltage and peak currents.

The proposed control technique based on the hybrid modulation has some limitations. Firstly, it is very useful to reduce peak-to-peak output voltage and peak currents significantly only when modulation frequency is higher than the open loop gain crossover frequency. For modulation frequencies lower than the crossover frequency this technique is much less effective. Secondly, it is very useful to reduce peak-to-peak output voltage significantly only when output capacitor with capacitive reactance much lower than equivalent series resistance is used (as in case of output electrolytic capacitor).The technique proposed is less effective to reduce peak-to-peak output voltage when output capacitor with capacitive reactance much higher than equivalent series resistance is used (as in case of output ceramic capacitor). However, peak currents can be reduced as effectively as in case when electrolytic capacitors are used at output of SMPC.

\section{ACKNOWLEDGEMENTS}

Support for this work was provided by the Riga Technical University through the Scientific Research Project Competition for Young Researchers No. ZP-2017/6.

\section{REFERENCES}

[1] Z. Wei, "The Electromagnetic Interference Model Analysis of the Power Switching Devices," Indonesian Journal of Electrical Engineering and Computer Science, Vol.11, No.1, pp. 167-72., Jan. 2013.

[2] M.M. Jha, K.B. Naik, and S.P. Das, "Impact of Parasitic Components on EMI Generated by SMPS," International Journal of Power Electronics and Drive System, Vol.2, No.3, September 2012, pp. 305-312.

[3] A. Bendicks, H. Haverland, S. Frei, N. Hees, M. Wiegand, "Application of spread spectrum techniques for the reduction of disturbances of automotive power electronic converters,". Proc. of International Conference on Electrical and Electronic Systems, Hybrid Electrical Vehicles and Electrical Energy Management, Bamberg, Germany, May 17 - 18, 2017, pp.1-8.

[4] K. Mainali, R. Oruganti, "Conducted EMI Mitigation Techniques for Switch-Mode Power Converters: A Survey," IEEE Transactions on Power Electronics, vol. 25, no. 9, pp. 2344-2356, 2010.

[5] M.Y. Hariyawan, R. Hidayat, and E. Firmansyah, "The Effects of Spread Spectrum Techniques in Mitigating Conducted EMI to LED Luminance," International Journal of Electrical and Computer Engineering (IJECE), Vol.6, No.3, pp. 1332-1343, June 2016.

[6] D. Stepins, J. Huang, "Effects of Switching Frequency Modulation on Input Power Quality of Boost Power Factor Correction Converter," International Journal of Power Electronics and Drive System (IJPEDS), Vol.8, No.2, pp.882-899, June 2017.

[7] D. Hamza, Q. Mei, and P. K. Jain, "Application and stability analysis of a novel digital active EMI filter used in a grid-tied PV microinverter module," IEEE Trans. Power Electron., vol. 28, no. 6, pp. 2867-2874, June 2013.

[8] B. Weiss, R. Reiner, R. Quay, P. Waltereit, F. Benkhelifa, M. Mikulla, M. Schlechtweg, and O. Ambacher, "Switching frequency modulation for GaN-based power converters," Proc. of 2015 IEEE Energy Conversion Congress and Exposition (ECCE), Montreal, Quebec, Canada, Sep. 20, 2015, pp.4361-4366.

[9] D. Gonzalez, J. Balcells, A. Santolaria, J. Bunetel, J. Gago, D. Magnon, S. Brehaut, "Conducted EMI Reduction in Power Converters by Means of Periodic Switching Frequency Modulation," IEEE Transactions on Power Electronics, vol.22, no.6, pp. 2271-2281, Nov. 2007.

[10] D. Stepins, "An improved control technique of switching frequency modulated power factor correctors for low THD and high power factor," IEEE Transactions on Power Electronics, Vol.31, No.7, pp.5201-5214, July 2016.

[11] K. Tse, H. Chung, S. Hui, H. So, "Comparative Study of Carrier- Frequency Modulation Techniques for Conducted EMI Suppression in PWM Converters," IEEE Transactions on Industrial Electronics, vol. 49, no.3. pp. 618-627, June 2002.

[12] A. M. Trzynadlowski, K. Borisov, Y. Li, and L. Qin, "A novel random PWM technique with low computational overhead and constant sampling frequency for high-volume, low-cost applications," IEEE Trans. Power Electron., vol. 20, no. 1, pp. 116-122, Jan. 2005.

[13] D. Stepins, J. Jankovskis, „Reduction of output voltage ripples in frequency modulated power converter,” Electronics and Electrical Engineering, vol.119, no.3, pp. 45 - 48, Mar. 2012. 
[14] A. Santolaria, "Effects of Switching Frequency Modulation on the Power Converter's Output Voltage," IEEE Transactions on Industrial Electronics, Vol.56, No.7, pp. 2729-2737, July 2009.

[15] D. Stepins, "Effect of Frequency Modulation on Input Current of Switch-Mode Power Converter," Proc. of the 39th Annual Conference of IEEE Industrial Electronics Society (IECON 2013), Austria, Vienna, Nov. 10-13, 2013, pp.683-688.

[16] D. Stepins, "Examination of influence of periodic switching frequency modulation in $\mathrm{dc} / \mathrm{dc}$ converters on power quality on a load," Proc. of the 11th Biennial Baltic Electronics Conference, Tallinn, Estonia, Oct. 6-8, 2008, pp.285-288.

[17] D. Stepins, J. Jankovskis "Study of Frequency Modulated Boost Converter Operating in Discontinuous Conduction Mode," Electronics and Electrical Engineering, Vol.122, No.6, pp. 41-44, June 2012.

\section{BIOGRAPHIES OF AUTHORS}

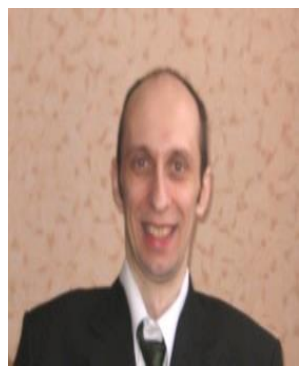

Deniss Stepins received the B.Sc., M.Sc. (with honors) and Dr.Sc.ing degrees in electronics from Riga Technical University, Riga, Latvia, in 2004, 2006 and 2011 respectively. He is currently a senior researcher and assistant professor in the Department of Electronics and Telecommunications, Riga Technical University. He is an author or co-author of more than 40 research papers. His research interests include EMI reduction techniques applied to switching power converters, control of switch-mode power supplies and power factor correction. He is currently IEEE member.

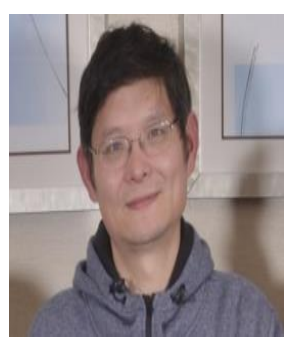

Jin Huang received the B.Sc. degree from Shanghai Jiaotong University, Shanghai, China, in 1992, and the M.Sc. and Ph.D. degrees from the Huazhong University of Science and Technology, Wuhan, China, in 2003 and 2009, respectively. In 2000, he joined Huazhong University of Science and Technology as a Lecturer. He is currently an Associate Professor in the School of Electrical and Electronic Engineering. His research interests include the control technique, EMC and reliability of power electronics devices.

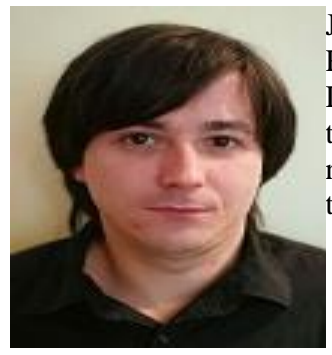

Janis Audze received the B.Sc. and M.Sc. degrees in electronics from Riga Technical University, Riga, Latvia, in 2008 and 2010 respectively. He is currently pursuing a $\mathrm{PhD}$ degree in the Department of Electronics and Telecommunications, Riga Technical University, Latvia. His PhD thesis is devoted to wireless power transfer technology and is supervised by Dr. D. Stepins. His research interests include wireless power transfer, resonant converters and novel PCB design techniques. 